\title{
Plasma fatty acids and lipid hydroperoxides increase after antibiotic therapy in
} cystic fibrosis

\author{
I. Durieu*, F. Abbas-Chorfa* , J. Drai ${ }^{\dagger}$, J. Iwaz" ${ }^{\#}$ J-P. Steghens ${ }^{+}$, M. Puget*, \\ R. Ecochard ${ }^{\#}$ and G. Bellon ${ }^{\S}$
}

\begin{abstract}
The present authors investigated whether cystic fibrosis is linked to a defect in fatty acids and assessed the impact of the main patients' characteristics on the levels of several fatty acids, mostly during respiratory exacerbation and after antibiotic therapy.

Fatty acid phospholipid and cholesteryl ester levels were measured in stable-state patients and controls. No differences were found concerning either the fractions of palmitic and oleic acids or the cholesteryl esters of $\alpha$-linolenic and arachidonic acids. However, phospholipids of $\alpha$-linolenic and arachidonic acids, as well as cholesteryl esters and phospholipids of stearic and linoleic acids, were lower in patients than in controls, but fractions of dihomo- $\gamma$-linolenic, docosatetraenoic, docosapentaenoic, palmitoleic and eicosatrienoic acids were higher.

Fatty acid levels, oxidative stress markers, nutrients, body mass index and forced expiratory volume in one second (FEV1) were measured in patients before and after antibiotic courses for bronchial exacerbation. After adjustments, palmitic, stearic, $\alpha$-linolenic, linoleic, arachidonic, palmitoleic and oleic acids generally decreased during exacerbation but almost all increased after antibiotic courses. Nearly all fractions increased along with FEV 1 and a positive relationship linked fatty acids to lipid hydroperoxides.
\end{abstract}

There was no general drop in fatty acids. Patients' fatty acid profiles depended on the pulmonary function and the inflammation state.

KEYWORDS: Body mass index, cystic fibrosis, fatty acids, forced expiratory volume, lipid hydroperoxide, vitamins

ystic fibrosis $(\mathrm{CF})$ is a severe genetic autosomal disorder caused by mutations of the cystic fibrosis transmembrane regulator (CFTR) gene. The main clinical manifestations include pancreatic insufficiency and bronchopulmonary complications. Clinical deterioration is characterised by nutritional disorders of complex origin and pulmonary bacterial colonisation, with intermittent exacerbations leading ultimately to respiratory failure.

Pancreatic insufficiency is thought to lower fatty acid (FA) levels [1], which contributes to the pulmonary involvement. Indeed, the relationships between low levels of FA and pulmonary function in CF children have already been addressed [2] and essential fatty acid (EFA) deficiency has been considered as a predisposing factor for pulmonary bacterial infection in $\mathrm{CF}$ infants [3]. Among the factors that may combine to affect the FA profile in CF patients, the following have been noted. 1) Low fat diet (previously used in older CF patients),
2) fat malabsorption $[3,4], 3)$ increased calorie supply to restore energy [5], 4) increased metabolism of EFA and overproduction of eicosanoids $[6], 5)$ increased turnover of FAs in cell membranes $[7], 6)$ increased peroxidation of polyunsaturated FAs [8], 7) defect of desaturase activity [3,9], and 8) specific genotype-linked basic defects [9-11].

Plasma fatty acid profiles in CF patients have been frequently studied since 1962 [1-4, 12-14], but the reported profiles were quite variable and comparing them is very difficult, not only because of differences in target FAs and patient selection, but also because the background diets and FA sources differ between countries and because the clinical management of the disease has been ever-changing. However, it has been possible to link discrepancies concerning the levels of some FAs to patient selection, age, pancreatic status, or genotype [10]. In contrast, EFA deficiency in CF patients is largely accepted, especially linoleic acid (C18:2n-6) deficiency [4, 10, 13].
AFFILIATIONS

*Dept of Internal Medicine and Cystic Fibrosis, Adult Centre, and ${ }^{\S}$ Dept of Paediatrics and Cystic Fibrosis, Paediatric Centre, Université Claude Bernard and Hospices Civils de Lyon, and

'Dept of General, Metabolic and Molecular Biochemistry, Hospices Civils de Lyon, Centre Hospitalier Lyon-Sud, Pierre-Bénite Cedex, and +Federation of Biochemistry, Université Claude Bernard and Hospices Civils de Lyon, Hôpital Edouard Herriot, and "Dept of Biostatistics, Hospices Civils de Lyon, Lyon Cedex, France.

CORRESPONDENCE

I. Durieu: Cystic fibrosis: Adult Centre: Dept of Internal Medicine, Centre Hospitalier Lyon-Sud, 69495 Pierre-Bénite Cedex, France. Fax: 33 478863264

E-mail: isabelle.durieu@chu-lyon.fr

Received:

January 042006

Accepted after revision:

January 192007

\section{SUPPORT STATEMENT}

The contribution of F. Abbas-Chorfa was partly supported by a grant from the Association de Recherche en Médecine Interne (Lyon, France).

STATEMENT OF INTEREST

None declared.

European Respiratory Journal

Print ISSN 0903-1936

Online ISSN 1399-3003 
In the present study, the plasma levels of several FAs in children and adult CF patients in three clinical conditions (stable state, bronchial exacerbation, and after antibiotic therapy) were measured concomitantly. The objective was to determine whether exacerbation of the respiratory disease and its antibiotic treatment affect FA status, as previously demonstrated for the oxidative status [15].

\section{SUBJECTS AND METHODS}

\section{Study subjects}

From November 1999 to March 2001, 296 consecutive CF patients attending paediatric and adult $\mathrm{CF}$ centres in Lyon (France) were prospectively included; their main characteristics by age class are shown in table 1 . Briefly, the study included 142 males and 154 females. At inclusion, CF patients' ages ranged 6 months to 45 yrs (mean \pm SD $13 \pm 9.2$ yrs; $25 \%$ aged $\geqslant 18$ yrs). Of these, 220 participated in full laboratory tests for the FA profile in a stable state (same-sex ratio, $12 \pm 9.4 \mathrm{yrs} ; 22 \%$ aged $\geqslant 18 \mathrm{yrs})$.

The diagnosis of CF was established by clinical picture and two elevated sweat chloride concentrations $\left(>60 \mathrm{mEq} \cdot \mathrm{L}^{-1}\right)$ or evidence of mutations in both CFTR alleles [16]. At inclusion, nearly $85 \%$ of patients had a pancreatic insufficiency. These were given pancreatic enzymes, 7,500 to 750,000 IU daily, according to diet, patient weight and frequency of abdominal symptoms.

The patients or their parents received regular dietary counselling in agreement with the current consensus reports on nutrition for paediatric and adult patients $[17,18]$, particularly with regard to fat intake (35-40\% of daily calories). The caloric supply was estimated on weight gain and fat stores, and was monitored to insure a steady weight gain in growing children and a stable weight in adults. Patients with vitamin A or vitamin E deficiency received an adequate supplementation according to their individual needs. The recommended dose of vitamin $\mathrm{A}$ for children $>8 \mathrm{yrs}$ and adults is $10,000 \mathrm{IU} \cdot$ day $^{-1}$. that of vitamin E is 200-400 IU $\cdot$ day $^{-1}$. These doses are practically halved for children aged 1-3 yrs. Vitamin checks were carried out every 6 months. The values considered as normal were $1.4-3.2 \mu \mathrm{mol} \cdot \mathrm{L}^{-1}$ for vitamin $\mathrm{A}$ and 20-35 $\mu \mathrm{mol} \cdot \mathrm{L}^{-1}$ for vitamin E. The above-mentioned doses were not augmented during exacerbation episodes. All

\begin{tabular}{|c|c|c|c|c|c|}
\hline $\begin{array}{l}\text { Age group } \\
\text { yrs }\end{array}$ & Patients & $M / F$ & Height $\mathrm{cm}$ & Weight kg & BMI $\mathbf{k g} \cdot \mathrm{m}^{-2}$ \\
\hline$<3$ & 31 & $14 / 17$ & $78.2 \pm 10.2$ & $10.0 \pm 2.6$ & $16.2 \pm 1.8$ \\
\hline $3-7$ & 50 & $27 / 23$ & $105.8 \pm 8.9$ & $16.9 \pm 3.1$ & $14.9 \pm 1.3$ \\
\hline $7-12$ & 73 & $28 / 45$ & $132.6 \pm 9.6$ & $27.6 \pm 6.4$ & $15.3 \pm 2.6$ \\
\hline $12-15$ & 40 & $19 / 21$ & $151.9 \pm 11.7$ & $40.3 \pm 10.2$ & $17.2 \pm 2.1$ \\
\hline $15-18$ & 28 & $12 / 16$ & $162 \pm 9.2$ & $47.8 \pm 9.9$ & $17.9 \pm 1.8$ \\
\hline$\geqslant 18$ & 74 & $42 / 32$ & $167 \pm 8.9$ & $53.4 \pm 8.9$ & $18.7 \pm 3.1$ \\
\hline
\end{tabular}

Data are presented as $\mathrm{n}$ or mean $\pm \mathrm{SD}$. M: male; F: female; BMI: body mass index patients had at least one measurement in stable-state. Among these, 70 patients had measurements during exacerbation: 43 had one episode, 23 had two episodes, and four patients had three episodes.

Antibiotic treatment was decided whenever the usual criteria of pulmonary exacerbation were observed [19]. The adequate antibiotics were prescribed for 2 weeks according to sputum test results. Usually, oral antibiotics were used against Staphylococcus aureus (except for some methicillin-resistant strains) and intravenous association of $\beta$-lactams or cephalosporins and tobramycin were used against Pseudomonas aeruginosa; $90 \%$ of the antibiotic courses were given at home.

Three clinical situations were distinguished for clinical and biological evaluation, as follows. 1) Stable-state, 2) acute bronchial exacerbation requiring antibiotic therapy, and 3) antibiotic course postexacerbation. The control group for FA analyses included 29 subjects: 22 children seen before orthopaedic surgery without any treatment and seven healthy young adult volunteers attending a phase I clinical trial centre (22 males; mean \pm SD $14 \pm 14$ yrs). With the approval of the local ethics committee, the laboratory analyses on the control group were carried out on fasting blood samples taken during the planned follow-up.

\section{Study design}

FA deficiency was assessed through comparison of FA profiles between CF patients and healthy controls. The variation of plasma levels of some FAs according to the body mass index (BMI), the forced expiratory volume in one second (FEV1), the clinical state of the disease, and the levels of some nutrients and oxidative markers was assessed using regression analyses.

\section{Methods}

The BMI (weight $(\mathrm{kg}) /$ height squared $\left(\mathrm{m}^{2}\right)$, taken in a recumbent position) was measured in $\mathrm{CF}$ patients at each visit, especially at the end of each antibiotic course. As the distributions of normal BMI values according to age are not symmetrical, the authors preferred to express the BMI values relative to the patients as percentiles of the normal values rather than z-scores. For clarity, the mean evolution of BMI in the present study's CF patients was plotted against the normal BMI for males and females (fig. 1) [20].

The FEV1 (\% predicted) was assessed and expressed as a percentage of the age, height and sex expected values [21, 22]. Microbiological sputum cultures were performed to assess bronchial bacterial colonisation. Patients $<6$ yrs of age, as well as patients with severe acute pulmonary exacerbation, were unable to perform spirometric tests.

Immediately after blood sampling (fasted patients) and centrifugation, $100-\mu \mathrm{L}$ aliquots of plasma were separated and stored at $-20^{\circ} \mathrm{C}$ until analysis for malondialdehyde (MDA), carotenoids and lipid hydroperoxides was carried out.

Methods used to assess vitamin A, vitamin E, carotenoids, MDA and lipid hydroperoxides have been previously detailed [15], and, briefly, are as follows. 1) Plasma concentrations of vitamin $\mathrm{A}$, vitamin $\mathrm{E}$, lutein and $\beta$-carotene were determined by high-performance liquid chromatography (HPLC) [23]; 2) MDA measurement was derived with a new, highly specific 

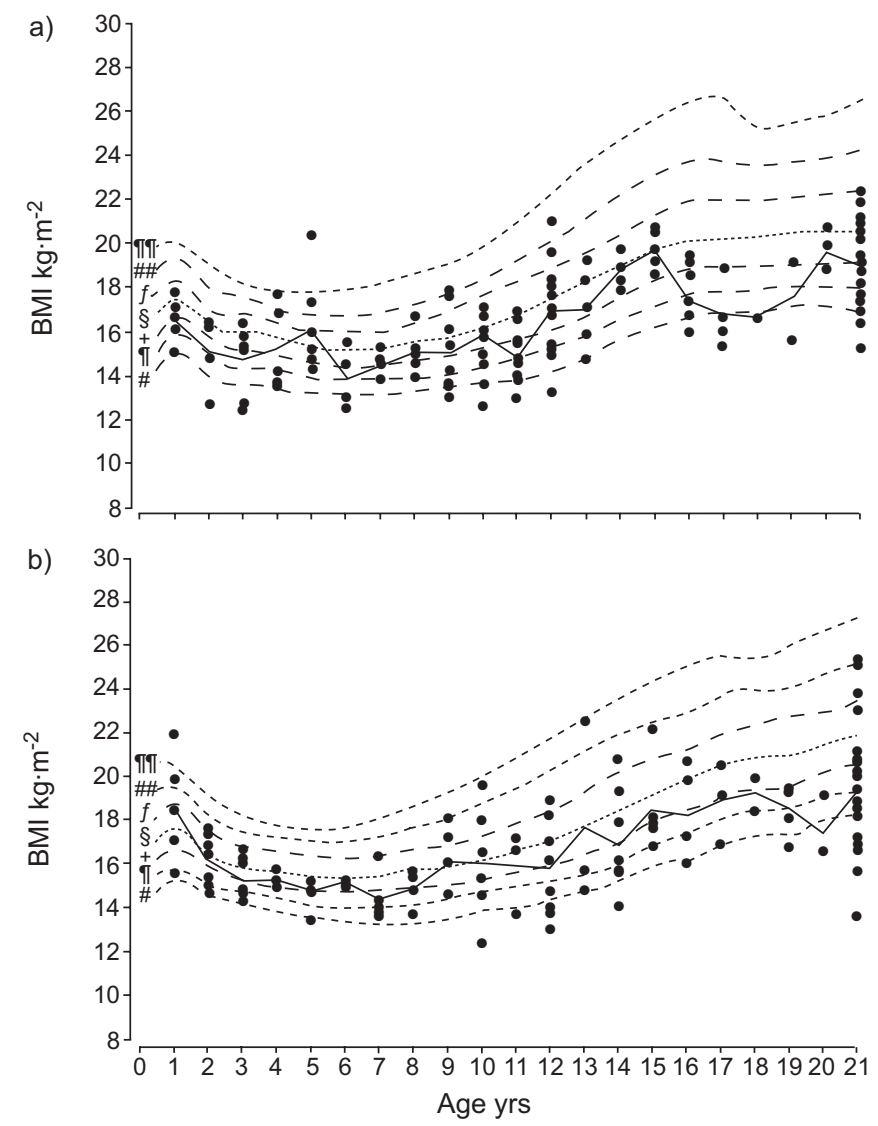

FIGURE 1. Distribution of body mass index (BMI) values according to age in a) female and b) male cystic fibrosis (CF) patients at inclusion. The mean BMls of CF patients are plotted on the diagrams of normal BMls for French males and females.

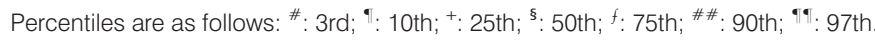

reagent for MDA (diaminonaphthalene) and quantified by HPLC-UV chromatography [24]; and 3) lipid hydroperoxides were measured using an automatic method derived from the method of JiANG et al. [25] and re-evaluated by NOUROOZ-ZADEH [26].

To quantify FAs, lipids were extracted using a chloroformmethanol mix $(1: 1, \mathrm{v} / \mathrm{v})$ and lipid classes were separated by thin-layer chromatography on silica gel plates (Merck 5721) using petroleum ether-ethylic ether-acetic acid $(1: 1: 1, \mathrm{v} / \mathrm{v} / \mathrm{v})$ as the developing solvent. Bromophenol blue-labelled individual phospholipids (PL) and cholesteryl esters (CE) bands were scraped off the plates into separate tubes. The PL fraction was saponified and transmethylated with sodium methylate, and the CE fraction was methylated with sulphuric acid and dehydrated methanol. The methyl esters of each fraction were removed by hexane and analysed by gas-liquid chromatography on a Fison GC-8000 gas chromatograph (Thermo Separation Products, Les Ulis, France) equipped with a CPSIL fused silica capillary column $(25 \mathrm{~m} \times 0.25 \mathrm{~mm}$ internal diameter) coated with $100 \%$ cyanopropyl siloxane.

Individual methyl ester components were identified by frequent comparisons with the retention times of a standard mixture of FA-methyl ester (FAME; SUPELCO ${ }_{\mathbb{B}}$ (Bellefonte, PA, USA), carefully prepared by weight and in which the weight percentage of each fatty acid is known. The results were thus expressed as a percentage of the total area of all FA peaks in each lipid fraction and were quantified $\left(\mathrm{mg} \cdot \mathrm{L}^{-1}\right)$ whenever possible.

\section{Analysis}

Log-transformed mean plasma levels of FAs in stable-state patients were compared with those found in the controls using the t-test. Paired t-tests for paired comparisons were used to test the change in BMI after antibiotic therapy. In order to explain the differences in FA profiles between the three clinical conditions, a regression analysis for repeated-measurement data was performed [27] using each patient as their own control; this was a multilevel model, with patient variation specified as a random effect at level 2 and the successive measurements at level 1 . This allowed the handling of situations with multiple measurements per patient in a given status; i.e. stable, exacerbation, etc. The potential independent predictors were introduced as fixed effects. These were age, FEV1, BMI and the clinical condition (stable, exacerbation, post-exacerbation antibiotic course). Being highly correlated, the effects of these variables were assessed separately, first by taking into account age and clinical condition as predictors, then by accounting for FEV1, BMI and clinical condition.

To analyse the relationship between oxidative status and FA levels, regression analyses were performed, once more using the same multilevel modelling process. FAs were the dependent variables and the oxidative markers were the potential independent predictors. Regressions were adjusted for age, FEV1, BMI and clinical condition. For comparison purposes, in the present assessment of the relationship between oxidative status and FA levels, all FA and oxidative marker values were standardised before their use in the regression analysis. Thus, a coefficient of +1 indicates a one-SD increase of the FA level per one-SD increase of the oxidative marker. Conversely, -1 indicates a one-SD decrease. Significance was defined as $\mathrm{p}<0.05$ in all analyses.

\section{RESULTS}

The detailed results of the comparison of plasma FAs with adjustment for age was made between CF patients in a stable state and controls (table 2). In summary, there were no significant differences with regard to the PL and CE fractions of palmitic (C16:0) and oleic (C:18) acids and to the PL fraction of docosahexaenoic acid (C22:6n-3). The plasma CE fractions of $\alpha$-linolenic acid (C18:3n-3) and arachidonic acid (C20:4n-6) were not different, but their PL fractions were lower in CF patients $(\mathrm{p}<0.005)$. The levels of CE and PL of both stearic acid (C18:0) and linoleic acid (C18:2n-6) were significantly lower in CF patients than in controls $(\mathrm{p} \leqslant 0.05)$. However, the PL levels of dihomo- $\gamma$-linolenic acid (C20:3n-6), docosatetraenoic acid (C22:4n-6), docosapentaenoic acid (C22:5n-6), palmitoleic acid (C16:1n-7), eicosapentaeonic (C:22), and eicosatrienoic acid (C20:3n-9) were higher in CF patients $(p \leqslant 0.05)$.

Variations in plasma FAs according to age, clinical condition, BMI and FEV1, as well as according to the oxidative markers were studied for palmitic, stearic, $\alpha$-linolenic, linoleic, arachidonic, palmitoleic and oleic acid (tables 3 and 4). After adjustment for FEV1, no significant variations were related to age, either in CF patients or in controls (not shown). The 


\begin{tabular}{|c|c|c|c|c|}
\hline TABLE : & \multicolumn{4}{|c|}{$\begin{array}{l}\text { Phospholipids }(\mathrm{PL}) \text { and cholesteryl esters (CE) of } \\
\text { plasma fatty acids measured in healthy controls } \\
\text { and stable-state cystic fibrosis (CF) patients at } \\
\text { inclusion }\end{array}$} \\
\hline \multicolumn{2}{|c|}{ Fatty acid fractions } & Healthy controls & CF patients & p-value \\
\hline $\mathbf{n}$ & & 29 & 220 & \\
\hline \multicolumn{5}{|c|}{ Palmitic acid } \\
\hline \multicolumn{2}{|c|}{$\mathrm{PL}$ C16:0 $\mathrm{mg} \cdot \mathrm{L}^{-1}$} & $222.86 \pm 45.29$ & $209.71 \pm 48.79$ & 0.215 \\
\hline \multicolumn{2}{|c|}{ EC C16:0 $\mathrm{mg} \cdot \mathrm{L}^{-1}$} & $78.62 \pm 16.57$ & $73.86 \pm 16.27$ & 0.220 \\
\hline \multicolumn{5}{|c|}{ Stearic acid } \\
\hline \multicolumn{2}{|c|}{$\mathrm{PL}$ C18:0 $\mathrm{mg} \cdot \mathrm{L}^{-1}$} & $133.03 \pm 25.03$ & $116 \pm 27.31$ & 0.002 \\
\hline \multicolumn{2}{|c|}{ EC C18:0 $\mathrm{mg} \cdot \mathrm{L}^{-1}$} & $6.91 \pm 1.68$ & $4.69 \pm 1.92$ & $<0.001$ \\
\hline \multicolumn{5}{|c|}{$\alpha$-Linolenic acid } \\
\hline \multicolumn{2}{|c|}{ PL C18:3n-3 mg. L $^{-1}$} & $2.38 \pm 1.09$ & $1.63 \pm 0.93$ & $<0.001$ \\
\hline \multicolumn{2}{|c|}{ EC C18:3n-3 mg. $\mathrm{L}^{-1}$} & $3.83 \pm 1.8$ & $3.47 \pm 1.93$ & 0.508 \\
\hline \multicolumn{5}{|c|}{ Linoleic acid } \\
\hline \multicolumn{2}{|c|}{ PL C18:2n-6 mg $\cdot \mathrm{L}^{-1}$} & $208.03 \pm 44.62$ & $153.17 \pm 47.95$ & $<0.001$ \\
\hline \multicolumn{2}{|c|}{ EC C18:2n-6 mg $\cdot \mathrm{L}^{-1}$} & $389.48 \pm 82.69$ & $311.45 \pm 111$ & $<0.001$ \\
\hline \multicolumn{5}{|c|}{ Arachidonic acid } \\
\hline \multicolumn{2}{|c|}{ PL C20:4n-6 mg. $\mathrm{L}^{-1}$} & $96.24 \pm 22.95$ & $82.2 \pm 22.71$ & 0.004 \\
\hline \multicolumn{2}{|c|}{ EC C20:4n-6 mg $\mathrm{L}^{-1}$} & $44.52 \pm 13.06$ & $44.01 \pm 16.48$ & 0.826 \\
\hline \multicolumn{5}{|c|}{ Palmitoleic acid } \\
\hline \multicolumn{2}{|c|}{ PL C16:1n-7 mg. $\mathrm{L}^{-1}$} & $5.09 \pm 2.26$ & $7.99 \pm 3.98$ & $<0.001$ \\
\hline \multicolumn{2}{|c|}{ EC C16:1n-7 mg $\cdot \mathrm{L}^{-1}$} & $17.6 \pm 6.65$ & $36.55 \pm 19.68$ & $<0.001$ \\
\hline \multicolumn{5}{|l|}{ Oleic acid } \\
\hline \multicolumn{2}{|c|}{ PL C18:1n-9 mg $\cdot \mathrm{L}^{-1}$} & $100.14 \pm 24.7$ & $107.5 \pm 28.08$ & 0.162 \\
\hline \multicolumn{2}{|c|}{ EC C18:1n-9 mg $\cdot \mathrm{L}^{-1}$} & $147.52 \pm 30.43$ & $156.57 \pm 41.89$ & 0.291 \\
\hline \multicolumn{5}{|c|}{ Eicosapentaenoic acid } \\
\hline \multicolumn{2}{|c|}{ PL C22:5n-3 \% } & $0.83 \pm 0.16$ & $1.04 \pm 0.34$ & 0.002 \\
\hline \multicolumn{5}{|c|}{ Docosahexaenoic acid } \\
\hline \multicolumn{2}{|c|}{ PL C22:6n-3 \% } & $2.62 \pm 0.85$ & $2.38 \pm 0.86$ & 0.172 \\
\hline Dihomo- $\gamma-\mathrm{li}$ & blenic ac & & & \\
\hline PL C20:3r & & $3.01 \pm 0.53$ & $4.28 \pm 0.92$ & $<0.001$ \\
\hline EC C20:3 & & $0.79 \pm 0.27$ & $0.99 \pm 0.26$ & $<0.001$ \\
\hline Docosatetr & noic acic & & & \\
\hline PL C22:4r & & $0.44 \pm 0.11$ & $0.61 \pm 0.19$ & $<0.001$ \\
\hline Docosapen & enoic ac & & & \\
\hline PL C22:5r & & $0.35 \pm 0.13$ & $0.45 \pm 0.2$ & 0.010 \\
\hline Eicosatrien & c acid & & & \\
\hline PL C20:3r & & $0.18 \pm 0.1$ & $0.53 \pm 0.41$ & $<0.001$ \\
\hline EC C20:3 & & $0.03 \pm 0.04$ & $0.23 \pm 0.19$ & $<0.001$ \\
\hline
\end{tabular}

Data are presented as mean $\pm \mathrm{SD}$, unless otherwise stated. All t-tests were carried out on log-transformed values.

concentrations of the tested FA fractions were generally lower, though not significantly, during bronchial exacerbation than during stable state. However, nearly all these concentrations were significantly higher after antibiotic treatment than during bronchial exacerbation or stable state (table 3).

The concentrations of all tested FAs, except palmitoleic acid (C16:1n-7), increased significantly along with increasing FEV1. For instance, the concentration of the $\mathrm{CE}$ fraction of linoleic acid $(\mathrm{C} 18: 2 \mathrm{n}-6)$ increased by 1.36 times the SD of all the considered concentrations for every $1 \%$ increase of the FEV1. However, the higher concentrations found after antibiotic therapy remained so even after adjustment for FEV1. In addition, the effect of BMI was only significantly positive on the $C E$ fraction of linoleic acid, but was significantly negative on the PL fraction of palmitoleic acid; both effects reflecting EFA deficiency. Generally, the size effect (the extent of the increase or decrease) of FEV1 on FA concentrations was higher than that of BMI.

As for the oxidative markers, concentrations of vitamin $\mathrm{A}$, vitamin $\mathrm{E}, \beta$-carotene and lutein positively and significantly affected almost all tested FAs (table 4). However, while no generally significant relationship was observed between the plasma levels of tested FAs and total MDA, there was a positive and highly significant relationship between these levels and lipid hydroperoxides (table 4). The increase in plasma levels of tested FAs was rather homogeneous between $0.2-0.5$ SDs per SD increase in vitamin A, vitamin $\mathrm{E}, \beta$-carotene, lutein and lipid hydroperoxides.

In a stable state, the BMI values of the present study's patients were almost constantly below the 50th percentiles of the BMI values in the general population, whatever the age, in both males and females (fig. 1). The test on paired BMI measures in 50 patients treated with antibiotics for an exacerbation episode indicated that absolute BMI values increased significantly after 14 days of antibiotic therapy $(\mathrm{p}<0.0001)$. The same result was obtained when the test was carried out with the relative BMI values; i.e. the same percentile positions were observed for the BMIs of the patients with respect to the normal BMI curves $(\mathrm{p}=0.0014)$.

\section{DISCUSSION}

The present study comprised a large cohort of children and adult CF patients with FA measurements at different key moments of the disease. The study yielded representative results as to the plasma levels of major FAs and lipid peroxidation markers and showed interesting relationships between these levels and several important clinical and physiological parameters, such as bronchial infection, FEV1 and oxidation. More precisely, CF patients had EFA deficiencies but no general decrease in FAs; their FA profile depended on their clinical, nutritional, respiratory and oxidative status. In particular, FAs and lipid peroxidation markers increased after antibiotic treatment.

In the present study, analysis of both CE and PL fractions originated from the authors' personal observations that low levels of FA are detected earlier in the CE fraction than the PL. In addition, ARRANZ et al. [28] found that when the FA profile changes, the $\mathrm{CE}$ fraction is more sensitive to that change than the PL fraction. Besides, analysis of the FA composition of triacylglycerols is valid only after a strict 12-h fast because of the rapid exchange of lipids between the intestinal and the circulatory systems.

Biologically, the present results show that despite regular use of pancreatic enzymes and adequate nutritional supply, the patients retained some direct and indirect signs of EFA deficiency; i.e. low levels of the PL and CE of linoleic acid $(\mathrm{C} 18: 2 \mathrm{n}-6)$ and PL of linolenic acid (C18:3n-3) [10], and high levels of the PL and CE of n-7 and n-9 FAs [29], respectively. Moreover, in the relevant literature, the levels of arachidonic acid in CF patients have been found to be lower $[2,4,30]$, equivalent [10], or higher [11] than those of controls according 


\begin{tabular}{|c|c|c|c|c|c|}
\hline \multirow[t]{2}{*}{ Fatty acid fractions } & \multirow[t]{2}{*}{ Mean $\mathrm{mg} \cdot \mathrm{L}^{-1}$} & \multirow[t]{2}{*}{ FEV $_{1}$} & \multirow[t]{2}{*}{ BMI } & \multicolumn{2}{|c|}{ Clinical condition } \\
\hline & & & & During acute exacerbation & After antibiotic therapy \\
\hline \multicolumn{6}{|l|}{ Palmitic acid } \\
\hline PL C16:0 & 189.53 & $+0.39 *$ & -0.14 & -14.64 & $+38.07^{\star \star \star}$ \\
\hline CE C16:0 & 63.56 & $+0.14^{\star *}$ & +0.04 & +0.22 & $+5.92^{*}$ \\
\hline \multicolumn{6}{|l|}{ Stearic acid } \\
\hline PL C18:0 & 89.77 & $+0.39 * \star \star$ & 0 & -6.78 & $+10.86^{\star \star}$ \\
\hline CE C18:0 & 3.19 & $+0.02^{\star \star \star}$ & +0.01 & +0.17 & -0.05 \\
\hline \multicolumn{6}{|l|}{$\alpha$-Linolenic acid } \\
\hline PL C18:3n-3 & 1.28 & 0 & 0 & +0.39 & $+0.8^{\star \star \star}$ \\
\hline CE C18:3n-3 & 2.29 & $+0.01^{*}$ & +0.01 & -0.03 & $+1.1^{\star \star \star}$ \\
\hline \multicolumn{6}{|l|}{ Linoleic acid } \\
\hline PL C18:2n-6 & 108.65 & $+0.6^{* \star *}$ & +0.16 & -5.8 & $+21.36^{\star \star \star}$ \\
\hline CE C18:2n-6 & 201.47 & $+1.36^{\star \star \star}$ & $+0.86^{\star}$ & +0.2 & +18.94 \\
\hline \multicolumn{6}{|l|}{ Arachidonic acid } \\
\hline PL C20:4n-6 & 71.5 & $+0.23^{* * *}$ & -0.06 & -4.26 & $+6.62^{*}$ \\
\hline CE C20:4n-6 & 36.76 & $+0.13^{\star \star}$ & +0.05 & -1.39 & -0.05 \\
\hline \multicolumn{6}{|l|}{ Palmitoleic acid } \\
\hline PL C16:1n-7 & 8.33 & +0.01 & $-0.03^{\star}$ & -1.2 & $+2.87^{\star \star \star}$ \\
\hline CE C16:1n-7 & 33.68 & +0.08 & -0.05 & +0.44 & $+12.05^{\star \star \star}$ \\
\hline \multicolumn{6}{|l|}{ Oleic acid } \\
\hline PL C18:1n-9 & 96.42 & $+0.21^{\star}$ & -0.08 & -4.54 & $+24.56^{\star \star \star}$ \\
\hline CE C18:1n-9 & 141.11 & +0.22 & +0.13 & -6.45 & $+17.96^{\star \star}$ \\
\hline
\end{tabular}

Data are presented as the extent, in SDS, of the increase (+) or decrease (-) in the dependent variable (e.g. palmitic acid) per unit increase or decrease in the independent predictor (e.g. FEV1). ": Results of multilevel linear regressions are adjusted for all other variables. The differences for "acute exacerbation" and "after antibiotic therapy" are adjusted differences from the stable-state. ${ }^{*}: p<0.05 ;{ }^{* *}: p<0.01 ;{ }^{* *}: p<0.001$.

to age or to other characteristics. The present results, lower levels of the PL fraction, are in agreement with those of THOMPSON et al. [2], FARRELl et al. [4] and CHRISTOPHE et al. [30, 31], although they are in disagreement with those of FREEDMAN et al. [11].

Also, in consistent agreement with other studies [10, 13], the patients in the present study had high levels of eicosatrienoic acid (C20:3n-9), suggesting an underlying deficiency of n-6 fatty acids [29]. However, the present study did not show a significant difference in docosahexaenoic acid percentage (C22:6n-3) between CF patients and controls; which is not surprising given that the levels of $\alpha$-linolenic acid (C18:2 n-3, PL fraction), a precursor of C22:6n-3, were found to be only slightly lower in CF patients than in controls. This is in agreement with the findings of BENABDESLAM et al. [32], but again are in disagreement with those of FREEDMAN et al. [11], whose study showed decreased docosahexaenoic acid levels in affected tissues and plasma from CF patients compared with healthy controls. This discrepancy deserves further examination and studies involving cell membrane FAs and the relationship between plasma and tissue FA levels.

Clinically, the results of the present study show that plasma FA variations are independently linked to both bronchial exacerbation and FEV1, with the size effect of FEV1 being greater than that of BMI. Indeed, as previously demonstrated for the oxidative status [15], pulmonary dysfunction seems to be more important than nutritional disorders in controlling the plasma FA profile, except for EFA deficiency, because the BMI affects linoleic acid positively and palmitoleic acid negatively. This point deserves careful investigation because diet is the only source of EFAs and because fat malabsorption is commonly thought to cause EFA deficiency, while EFA deficiency is also a known cause of fat malabsorption [33, 34]. Furthermore, the transition from pulmonary inflammation to systemic inflammation should also be considered.

The higher levels observed for plasma FA, vitamin A and vitamin $\mathrm{E}$ after antibiotic therapy for bronchial exacerbation may be explained by a better nutritional status, a greater FEV1 and the control of the inflammatory process [35]. It has already been shown that the levels of antioxidants and lipid peroxidation markers were generally lower in $\mathrm{CF}$ patients than in controls, that they decreased during exacerbation and increased after antibiotic therapy, and that plasma measurements did not reflect the oxidative stress in the respiratory tract [15]. Increased levels of lipid hydroperoxides observed after antibiotic therapy may be explained by a higher oxygen concentration in airway mucus due to less bronchial obstruction. This augments the production of reactive oxygen species with antimicrobial properties to protect the respiratory tract 


\begin{tabular}{|c|c|c|c|c|c|c|}
\hline Fatty acid fraction & Vitamin A & Vitamin E & $\beta$-Carotene & Lutein & $\begin{array}{l}\text { Total malon- } \\
\text { dialdehyde }\end{array}$ & $\begin{array}{c}\text { Lipid hydro- } \\
\text { peroxides }\end{array}$ \\
\hline \multicolumn{7}{|l|}{ Palmitic acid } \\
\hline PL C16:0 mg $\cdot \mathrm{L}^{-1}$ & $+0.49 * \star \star$ & $+0.50 * \star \star$ & $+0.12^{*}$ & $+0.24^{\star \star \star}$ & $+0.14^{\star *}$ & $+0.51^{\star \star \star}$ \\
\hline \multicolumn{7}{|l|}{ Stearic acid } \\
\hline $\mathrm{PL}$ C18:0 mg $\cdot \mathrm{L}^{-1}$ & $+0.35^{\star \star \star}$ & $+0.50^{\star \star \star}$ & $+0.28^{\star \star \star}$ & $+0.35^{\star \star \star}$ & $+0.14^{\star \star \star}$ & $+0.42^{\star \star \star}$ \\
\hline CE C18:0 $\mathrm{mg} \cdot \mathrm{L}^{-1}$ & $+0.16^{\star \star}$ & $+0.34 * * *$ & $+0.41^{\star * *}$ & $+0.4^{\star \star \star}$ & +0.09 & $+0.15^{\star}$ \\
\hline \multicolumn{7}{|l|}{$\alpha$-Linolenic acid } \\
\hline 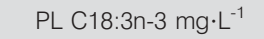 & $+0.23^{* * *}$ & $+0.19 * \star \star$ & -0.02 & $+0.13^{*}$ & -0.007 & $+0.23^{\star \star \star}$ \\
\hline CE C18:3n-3 mg. $\mathrm{L}^{-1}$ & $+0.23^{* * *}$ & $+0.21^{\star \star \star}$ & +0.11 & $+0.16^{\star \star}$ & +0.03 & $+0.19^{\star}$ \\
\hline \multicolumn{7}{|l|}{ Linoleic acid } \\
\hline CE C18:2n-6 mg $\cdot \mathrm{L}^{-1}$ & $+0.27^{\star \star \star}$ & $+0.39 * * *$ & $+0.34^{\star * *}$ & $+0.43^{* * *}$ & +0.07 & $+0.21^{\star \star \star}$ \\
\hline \multicolumn{7}{|l|}{ Arachidonic acid } \\
\hline $\mathrm{PL}$ C20:4n-6 mg $\cdot \mathrm{L}^{-1}$ & $+0.38^{* \star *}$ & $+0.45^{\star \star \star}$ & $+0.21 * \star \star$ & $+0.31^{\star \star *}$ & $+0.14^{\star *}$ & $+0.4^{\star \star \star}$ \\
\hline CE C20:4n-6 mg $\cdot \mathrm{L}^{-1}$ & $+0.25^{\star \star \star}$ & $+0.29 * \star \star$ & $+0.17^{\star \star}$ & $+0.16^{\star \star}$ & $+0.13^{\star}$ & $+0.22 * \star \star$ \\
\hline \multicolumn{7}{|l|}{ Palmitoleic acid } \\
\hline $\mathrm{PL}$ C16:1n-7 mg. $\mathrm{L}^{-1}$ & $+0.24^{\star \star \star}$ & $+0.18^{\star \star}$ & -0.11 & -0.04 & +0.06 & $+0.28^{\star \star \star}$ \\
\hline CE C16:1n-7 mg $\cdot \mathrm{L}^{-1}$ & $+0.23^{\star \star \star}$ & $+0.14^{\star}$ & $-0.13^{*}$ & -0.08 & +0.11 & $+0.23^{\star \star \star}$ \\
\hline \multicolumn{7}{|l|}{ Oleic acid } \\
\hline PL C18:1n-9 mg. $\mathrm{L}^{-1}$ & $+0.32^{\star \star \star}$ & $+0.35^{\star \star \star}$ & +0.08 & $+0.12^{*}$ & $+0.14^{*}$ & $+0.43^{\star \star \star}$ \\
\hline CE C18:1n-9 mg $\cdot \mathrm{L}^{-1}$ & $+0.32^{\star \star \star}$ & $+0.38^{\star \star \star}$ & $+0.22^{\star \star \star}$ & $+0.21^{* \star *}$ & $+0.18^{\star \star}$ & $+0.37^{\star \star \star}$ \\
\hline
\end{tabular}

$[36,37]$. Indeed, if it is accepted that membrane nicotinamine adenine dinucleotide phosphate hydrogen-oxidase is activated by arachidonic acid to produce hydrogen peroxide/peroxide dianion, it may be hypothesised that this enzyme participates in oxidative function recovery after antibiotic therapy.

Other results open the way to ancillary investigations. First, despite a controlled nutritional supply in line with the current recommendations, the present study's patients showed EFA deficiencies but no major plasma FA deficiencies. This calls for monitoring of EFA concentrations and for oral or parenteral substitution in case of deficiency. Secondly, plasma FA profile was affected by pulmonary function, antibiotic therapy for bronchial exacerbation and lipid hydroperoxides. The increase of FA and lipid hydroperoxides perhaps reflects the start of oxygen host-defence activity and it may be hypothesised that control of respiratory infection and local or systemic inflammation would contribute to a better EFA, and thus nutritional status, but only an interventional study would prove this. Thirdly, it would be interesting to clarify whether higher hydroperoxide levels observed after antibiotic treatment reflect a beneficial defence activity or deleterious oxidative damage.

In conclusion, the present report concerns only plasma fatty acid levels. Examination of other compartments would be helpful to link several miscellaneous results. Besides, examination of the present results in the light of specific cystic fibrosis genotypes would improve the pathophysiological explanation of the disturbed fatty acid metabolism in cystic fibrosis and improve treatment targeting.

\section{REFERENCES}

1 Hubbard VS, Dunn GD, di Sant'Agnese PA. Abnormal fatty-acid composition of plasma-lipids in cystic fibrosis. A primary or a secondary defect? Lancet 1977; 2: 1302-1304.

2 Thompson GN. Relationship between essential fatty acid levels, pulmonary function and fat absorption in preadolescent cystic fibrosis children with good clinical scores. Eur J Pediatr 1989; 148: 327-329.

3 Lloyd-Still JD, Bibus DM, Powers CA, Johnson SB, Holman RT. Essential fatty acid deficiency and predisposition to lung disease in cystic fibrosis. Acta Paediatr 1996; 85: 1426-1432.

4 Farrell PM, Mischler EH, Engle, MJ, Brown DJ, Lau SM. Fatty acid abnormalities in cystic fibrosis. Pediatr Res 1985; 19: 104-109.

5 Parsons HG, O'Louglin EV, Forbes D, Cooper D, Gall DG. Supplemental calories improve essential fatty acid deficiency in cystic fibrosis patients. Pediatr Res 1988; 24: 353-356.

6 Strandvik B, Brönnegerd M, Gilljam H, Carlstedt-Duke J. Relation between defective regulation of arachidonic acid release and symptoms in cystic fibrosis. Scand $J$ Gastroenterol 1988; 23S: 1-4. 
7 Rogiers V, Vercruysse A, Dab I, Baran D. Abnormal fatty acid pattern of the plasma cholesterol ester fraction in cystic fibrosis patients with and without pancreatic insufficiency. Eur J Pediatr 1983; 14: 39-42.

8 Wood L, Fitzgerald AD, Gibson PG, Cooper DM, Garg ML. Increased plasma fatty acid concentrations after respiratory exacerbations are associated with elevated oxidative stress in cystic fibrosis. Am J Clin Nutr 2002; 75: 668-675.

9 Bhura Bandali F, Suh M, Man SFP, Clandinin MT. The $\Delta$ F508 mutation in the cystic fibrosis transmembrane conductance regulator alters control of essential fatty acid utilization in epithelial cells. J Nutr 2000; 130: 2870-2875.

10 Strandvik B, Gronowitz E, Enlund F, Martinsson T, Wahlstrom J. Essential fatty acid deficiency in relation to genotype in patients with cystic fibrosis. J Pediatr 2001; 139: 650-655.

11 Freedman SD, Blanco PG, Zaman MM, et al. Association of cystic fibrosis with abnormalities in fatty acid metabolism. N Engl J Med 2004; 350: 560-569.

12 Kuo P, Huang N, Bassett D. The fatty acid composition of the serum chylomicrons and adipose tissue of children with cystic fibrosis of the pancreas. J Pediatr 1962; 60: 394-403.

13 Roulet M, Frascarolo P, Rappaz I, Pilet M. Essential fatty acid deficiency in well nourished young cystic fibrosis patients. Eur J Pediatr 1997; 156: 952-956.

14 Clandinin MT, Zuberbuhler P, Brown NE, Kielo ES, Goh YK. Fatty acid pool size in plasma lipoprotein fractions of cystic fibrosis patients. Am J Nutr 1995; 62: $1268-1275$

15 Lagrange-Puget $\mathrm{M}$, Durieu $\mathrm{I}$, Ecochard $\mathrm{R}$, et al. Longitudinal study of oxidative status in 312 cystic fibrosis patients in stable state and during bronchial exacerbation. Pediatr Pulmonol 2004; 38: 43-49.

16 Rosenstein BJ, Cutting GR. The diagnosis of cystic fibrosis: a consensus statement. Cystic Fibrosis Foundation Consensus Panel. J Pediatr 1998; 132: 589-595.

17 Borowitz D, Baker RD, Stalling V. Consensus report on nutrition for pediatric patients with cystic fibrosis. J Pediatr Gastroenterol Nutr 2002; 35: 246-259.

18 Yankaskas JR, Marschall BC, Sufian B, Simon RH, Rodman D. Cystic fibrosis adult care. Consensus conference report. Chest 2004; 125S: 1-39.

19 Rabin HR, Butler SM, Wohl ME, et al. Pulmonary exacerbations in cystic fibrosis. Pediatr Pulmonol 2004; 37: 400-406.

20 Sempé M, Rolland-Cachera MF. Etude séquentielle 1953-1975. CECDE. Tracés issus des courbes du carnet de santé. [Sequential study 1953-1975. CECDE. Graphs based on the growth curves from the children's health records.] Diffusion 97. Lyon, Meditions, 1997.

21 Bellon G, So S, Brun J, Adeleine P, Gilly R. Flow-volume curves in children in health and disease. Bull Eur Physiopathol Respir 1982; 17: 705-715.
22 Quanjer PH, Tammeling JE, Cotes JE, Pedersen OF, Pestin R, Jernault JC. Lung volumes and forced ventilatory flows. Eur Respir J 1993; 6: Suppl. 16, 15-40.

23 Steghens JP, Van Kappel AL, Riboli E, Collombel C. Simultaneous measurement of seven carotenoids, retinol and alpha-tocopherol in serum by high performance liquid chromatography. J Chromatogr B Biomed Sci Appl 1997; 694: 71-81.

24 Steghens JP, Van Kappel AL, Denis I, Collombel C. Diaminonaphtalene, a new highly specific reagent for HPLC-UV measurement of total and free malondialdehyde in human plasma or serum. Free Radic Biol Med 2001; 31: 242-249.

25 Jiang Z, Woollard ACS, Wolff SP. Lipid hydroperoxide measurement by oxidation of $\mathrm{Fe}^{2+}$ in the presence of xylenol orange. Comparison with the TBA assay and an iodometric method. Lipids 1991; 26: 853-856.

26 Nourooz-Zadeh J. Ferrous ion oxidation in presence of xylenol orange for detection of lipid hydroperoxides in plasma. Methods Enzymol 1999; 300: 58-62.

27 Goldstein H. Multilevel mixed linear model analysis using iterative generalized least squares. Biometrika 1986; 73: 43-56.

28 Arranz MI, Lasuncion MA, Perales J, et al. Fatty acid composition of lipoprotein lipids in hepatobiliary diseases. Eur J Clin Chem Clin Biochem 1996; 34: 701-709.

29 Siguel EN, Chee KM, Gong JX, Schaefer EJ. Criteria for essential fatty acid deficiency in plasma assessed by capillary column gas-liquid chromatography. Clin Chem 1987; 33: 1869-1873.

30 Christophe AB, Warwick WJ, Holman RT. Serum fatty acid profiles in cystic fibrosis patients and their parents. Lipids 1994; 29: 569-575.

31 Christophe A, Robberecht E. Current knowledge on fatty acids in cystic fibrosis. Prostaglandins Leukot Essent Fatty Acids 1996; 55: 129-138.

32 Benabdeslam H, Abidi H, Garcia I, Bellon G, Gilly R, Revol A. Lipid peroxidation and antioxidant defenses in cystic fibrosis patients. Clin Chem Lab Med 1999; 37: 511-516.

33 Strandvik B. Relation between essential fatty acid metabolism and gastrointestinal symptoms in cystic fibrosis. Acta Paediatr Scand Suppl. 1989; 363: 58-63.

34 Levy E, Garofalo C, Thibault L, et al. Intraluminal and intracellular phases of fat absorption are impaired in essential fatty acid deficiency. Am J Physiol 1992; 262: 319-326.

35 Vic P, Ategbo S, Gottrand F, et al. Nutritional impact of antipseudomonas intravenous antibiotic courses in cystic fibrosis. Arch Dis Child 1997; 76: 437-440.

36 Ganz T. Antimicrobial polypeptides in host defense of respiratory tract. J Clin Invest 2002; 109: 693-697.

37 Paredi P, Kharitonov SA, Barnes PJ. Analysis of expired air for oxidation products. Am J Respir Crit Care Med 2002; 166: S31-S37. 